\title{
CD44 crosslinking-mediated matrix metalloproteinase-9 relocation in breast tumor cells leads to enhanced metastasis
}

\author{
SHU-TINE PENG ${ }^{1,4}$, CHENG-HIS SU ${ }^{2}$, CHUN-CHI KUO ${ }^{3,5}$, CHEN-FU SHAW ${ }^{5}$ and HWAI-SHI WANG ${ }^{1}$ \\ ${ }^{1}$ Institute of Anatomy and Cell Biology, School of Medicine, Yang Ming University, Taipei; ${ }^{2}$ Department of Surgery, \\ Veterans General Hospital, Taipei; ${ }^{3}$ Department of Nursing, Tzuhui Institute of Technology, \\ Ping Tung; ${ }^{4}$ Institute of Physiology, School of Medicine, Yang Ming University, Taipei; \\ ${ }^{5}$ Department of Biological Sciences, National Sun Yat-Sen University, Kaohsiung, Taiwan, R.O.C.
}

Received May 21, 2007; Accepted July 17, 2007

\begin{abstract}
CD44 plays a major role in multiple physiological processes, including cell-cell adhesion, cell-substrate interaction, lymphocyte homing, and tumor metastasis. It has been reported that highly expressed CD44 in certain types of tumors is associated with the hematogenic spread of tumor cells. The ability of CD44 to bind hyaluronan has been shown to correlate with tumor cell invasiveness, and it is likely that this ability may enhance tumor cell migration at several points during metastasis. However, the mechanism as to how CD44 stimulates metastasis remains unknown. The human breast tumor cell line, MDA-MB-435s, was used to investigate the effect of antibody-mediated CD44 crosslinking on the cellular level and localization of matrix metalloproteinase-9 (MMP-9). Confocal microscopy and immunocytochemical analyses were performed to demonstrate colocalization of CD44 and MMP-9 after CD44 crosslinking. Furthermore, the CD44-MMP-9 complex was purified by immunoprecipitation. G8 myoblast monolayers were employed to evaluate the invasiveness of human breast tumor cells after CD44 crosslinking in the presence or absence of protease inhibitors. CD44 crosslinking augmented the level of MMP-9 in the membrane of human breast tumor cells and clustering of CD44 serves as an MMP-9 docking molecule allowing MMP-9 to retain its concentrated proteolytic activity on the cell surface. Furthermore, crosslinking of CD44 enhances the ability of breast tumor cells to invade G8 myoblast monolayers and migrate through the basal membranes which was inhibited in the presence of anti-MMP-9 antibody or the MMP inhibitors GM6001 or 1,10-phenanthroline. This study demonstrates for
\end{abstract}

Correspondence to: Dr Hwai-Shi Wang, Department of Anatomy, School of Medicine, Peitou, Taipei, Taiwan, R.O.C.

E-mail: hswang@ym.edu.tw

Key words: MMP-9, CD44, metastasis, breast tumor cells the first time that CD44 crosslinking leads to an enhanced level and relocation of MMP-9 in human breast tumor cells accompanied by increased tumor invasion and metastasis.

\section{Introduction}

Tumor metastasis is the process by which individual or a subset of cancer cells disseminate from a primary tumor to distant secondary tissues involving many factors such as interactions with the extracellular matrix, molecular signaling, and hereditary influences $(1,2)$. Dalchau et al (3) discovered that $\mathrm{T}$ lymphocytes contain CD44 antigens that are consistently overproduced by various types of tumor cells. CD44 is encoded by the $50-\mathrm{Kb}$ CD44 gene that includes 20 exons (4). Exon 6-15 $\left(\mathrm{V}_{1}-\mathrm{V}_{10}\right)$ located in the variable region is responsible for the generation of isoforms through extensive alternative splicing (4-6). The CD44 standard form (CD44s, 85-95 kDa) in which variant exons $\mathrm{V}_{1}-\mathrm{V}_{10}$ are not expressed is the most common and smallest CD44 isoform. CD44 is involved in the direction of cell-to-cell and cell-to-intercellular matrix interactions (7-9) and can be activated using cytokines or antibodies which increase the affinity (10-12) for its main ligand hyaluronan $(13,14)$. Interestingly, the use of antibodies to crosslink CD44 strengthens the CD44-hyaluran binding (15). Binding of CD44 with hyaluronan affects cell adhesion to extracellular matrix components which is implicated in subsequent cell migration and metastasis (16).

Various types of highly developed tumors exhibit substantial levels of CD44 which suggested that CD44 is directly related to tumor invasion and metastasis $(17,18)$. Antibodiesand hyaluronan-fragment-mediated CD44 crosslinking induces the production of adhesion molecules, including lymphocyte function-associated antigen (LFA-1), very late antigen-4 (VLA-4), VCAM-1, and ICAM-1 (19-21). Bourguignon et al (22) discovered that the ligation of hyaluronan and CD44v3 enhances the interaction between $\mathrm{CD} 44 \mathrm{v} 3$ and $\mathrm{T}$ lymphoma invasion and metastasis 1 (Tiam1) proteins, activates Rac 1 signaling, and promotes breast tumor cell migration. In addition, $\mathrm{c}$-Src kinase, Ras, protein kinase $\mathrm{C}$, and IкB kinase 1 and 2 were found to be participants in the signaling pathways of hyaluronan stimulation $(22,23)$, illustrating that CD44 acts as a signaling molecule. In fact, hyaluronan receptor-CD44 
complexes play a crucial role in adhesion and the growth and spread of various tumor cells $(8,24-26)$.

Matrix metalloproteinases (MMPs) have been considered as crucial molecules aiding tumor cells during metastasis and are members of a group of 28 proteases located within the extracellular matrix and involved in its degradation. Because of the extracellular matrix component-degrading capacity of MMPs, they participate in tumor cell invasion and migration (27). MMP-9 (gelatinase B, $92 \mathrm{kDa} ; 28$ ) belongs to the gelatinase class of MMPs and is characterized by the presence of three repeating fibronectin-type II domains near the catalytic domain that enhances its interaction with collagens and gelatins $(29,30)$ and plays an important role in tumor cell invasion and migration (2).

The interrelatedness of CD44 activation and MMP-9 gene expression and protein levels, and its effect on metastasis has been widely reported for various types of tumor cells. Yu and Stamenkovic (31) demonstrated that CD44 associates with a proteolytic form of MMP-9 on the surface of mouse mammary carcinoma and human melanoma cells forming a complex that promotes tumor cell invasion of G8 myoblast monolayers. Interestingly, hyaluronan oligosaccharides that bind the CD44 receptors induce MMP-9 expression in murine 3LL tumor cells via receptor, but not CD44-receptor, mediated mechanism (32). CD44 and hyaluronan modulated leukocyte migration in a mouse zymosan air-pouch inflammation model also involved MMP-9 (33) and CD44 activation also led to an increased invasion and expression of MMP-9 in a human colorectal cell line (34). Recently, it has been shown that in a colon cancer cell line, dentin matrix protein 1 was involved in bridging MMP-9 to cell surface receptors, including CD44 (35). Those studies have important pharmacological applications as demonstrated by Annabi et al (36) who developed the synthetic peptide, PCK3145, that inhibits MMP-9 secretion and triggers CD44 cell surface shedding in a fibrosarcoma cell line, and thus exhibits an antagonistic effect on tumor cell metastasis.

Here, we used a human breast tumor cell line exhibiting large quantities of CD44 receptor and evaluated the effect of CD44 crosslinking on the intra- and intercellular level of MMP-9. In addition, in vitro assays were conducted to determine whether MMP-9 is involved in tumor cell migration and metastasis after CD44 crosslinking.

\section{Materials and methods}

Cell cultures. Human breast tumor cell line (MDA-MB-435s) and mouse myoblast cell line (G8) were obtained from the Food Industry Research and Development Institute (Hsinchu, Taiwan). MDA-MB-435s cells were cultivated in Leibovitz's L-15 medium supplemented with $15 \%$ fetal bovine serum (FBS) (Hyclone, Logan, UT, USA), $10 \mu \mathrm{g} / \mathrm{ml}$ insulin, $100 \mathrm{U} / \mathrm{ml}$ penicillin, and $100 \mu \mathrm{g} / \mathrm{ml}$ streptomycin. Cells of the mouse myoblast cell line (G8) were grown on collagen-coated dishes containing DMEM, supplemented with $10 \%$ FBS, $10 \%$ horse serum, $100 \mathrm{U} / \mathrm{ml}$ penicillin, and $100 \mu \mathrm{g} / \mathrm{ml}$ streptomycin.

Crosslinking of CD44. Cells were cultured to subconfluence and then incubated with mouse anti-CD44 antibody $(10 \mu \mathrm{g} / \mathrm{ml})$ (Newmarker, Fremont, CA, USA) for $1 \mathrm{~h}$ at $37^{\circ} \mathrm{C}$. After washing the cells three times, $1 \mu \mathrm{g} / \mathrm{ml}$ of goat anti-mouse IgG-Fc (Bethyl, Montgomery, TX, USA) was added as the second antibody for CD44 crosslinking.

Flow cytometric analysis. Suspended breast tumor cells $\left(5 \times 10^{6}\right.$ cells $\left./ \mathrm{ml}\right)$, with or without CD44 crosslinking, were incubated for $45 \mathrm{~min}$ at $4^{\circ} \mathrm{C}$ with $150 \mu \mathrm{l}$ of appropriate FITC-conjugated antibody solution $(10 \mu \mathrm{g} / \mathrm{ml})$, washed with phosphate-buffered saline (PBS), spun down, and then fixed in $1.5 \mathrm{ml}$ of $4 \%$ paraformaldehyde. Negative control samples were incubated with PBS in place of the primary antibody. A Becton-Dickinson FACSCalibur Analytic Flow Cytometer (Palo Alto, CA, USA) was used to analyze antibody binding.

Immunocytochemistry of breast tumor cells. Staining was performed on fixed, non-permeabilized monolayers of breast tumor cells grown on glass tissue culture slides. Cells were washed with PBS and fixed with $0.05 \%$ glutaraldehyde for $30 \mathrm{~min}$ at $37^{\circ} \mathrm{C}$. Monolayers were incubated with $5 \%$ non-fat milk in PBS for $25 \mathrm{~min}$ at room temperature to block nonspecific binding. Mouse anti-CD44 mAb (1:100) and rabbit anti-MMP-9 pAb (1:100) were added and the slides were incubated for $75 \mathrm{~min}$ at room temperature. The secondary antibodies were rhodamine-conjugated donkey anti-mouse Ab (1:100) or FITC-conjugated goat anti-rabbit Ab (1:100). Cells were incubated with secondary antibody for $60 \mathrm{~min}$ at room temperature and then mounted with mounting medium (Vector, North Hollywood, CA, USA). Observations were performed with a confocal laser scanning microscope (Leica, Bensheim, Germany) using a 100x/1.30 oil immersion objective and an appropriate filter.

Immunoblotting and immunoprecipitation techniques. For immunoblotting on polyvinylidene difluoride (PVDF) filter membranes, cells were pooled and briefly rinsed with PBS. The cell pellets were lysed in $1 \mathrm{ml}$ of lysis buffer consisting of PBS, $1 \%$ sodium dodecyl sulfate (SDS) supplemented with $0.5 \mathrm{mM}$ phenylmethysulfonyl fluoride, $10 \mu \mathrm{g} / \mathrm{ml}$ leupeptin, $10 \mu \mathrm{g} / \mathrm{ml}$ aprotinin, $5 \mu \mathrm{g} / \mathrm{ml}$ pepstatin, $10 \mu \mathrm{g} / \mathrm{ml}$ soybean trypsin inhibitor, and $0.5 \mathrm{mM}$ dithiothreitol. The supernatant was removed after centrifugation for $20 \mathrm{~min}$ at $2,650 \mathrm{rpm}$ at $4^{\circ} \mathrm{C}$, and then ultracentrifuged at 55,000 rpm for $1 \mathrm{~h}$ at $4^{\circ} \mathrm{C}$. The supernatant contains the cytosolic fraction and the pellet is the membrane fraction. The media were also collected, concentrated by Centricon YM-30, and lyophilized. The samples were analyzed by SDS-PAGE using a $10 \%$ polyacrylamide gel. Separated polypeptides were then transferred onto PVDF membranes. After blocking nonspecific sites with $5 \%$ non-fat milk, the PVDF membranes were incubated with each of the specific immunoreagents [e.g., rat anti-CD44 Ab (5 $\mu \mathrm{g} / \mathrm{ml})$, and rabbit anti-MMP-9 Ab $(5 \mu \mathrm{g} / \mathrm{ml})]$, followed by an incubation with horseradish peroxidase-labeled immunoreagents (e.g., goat anti-rat Ab, goat anti-rabbit $\mathrm{Ab}$, or goat anti-mouse $\mathrm{Ab}$ ). The blots were developed using the ECL system (Amersham Biosciences, Piscataway, NJ, USA).

For analyzing the complex formation between CD44 and MMP-9, MDA-MB-435s cells (with or without CD44 crosslinking for $12 \mathrm{~h}$ ) were solubilized by lysis buffer and then ultracentrifuged to separate cytosolic and membranous 
fractions. The media were also collected and either immunoprecipitated with mouse anti-CD44 mAb $(2 \mu \mathrm{g}$ of primary antibody per $1 \mathrm{mg}$ of protein sample; $0.6 \mu \mathrm{g}$ of primary antibody per $1 \mathrm{ml}$ medium) overnight at $4^{\circ} \mathrm{C}$, and then immunoblotted with anti-MMP-9, or immunoprecipitated with MMP-9 antibody before being immunoblotted with anti-CD44. Proteins were resolved by $12 \%$ SDS-PAGE, transferred to PVDF and subsequently probed with mAbs as indicated. Immunoreactive polypeptides were visualized using horseradish peroxidase-labeled secondary antibodies and the ECL detection system.

Gelatin zymography. Gelatin zymography was carried out as described by Shi et al (37) with some modifications. Briefly, gelatin $(1.5 \mathrm{mg} / \mathrm{ml})$ as a substrate was copolymerized with regular $10 \%$ SDS-polyacrylamide gel. Electrophoresis was performed at a constant current of $15 \mathrm{~mA}$. After electrophoresis, the gel was washed with $2.5 \%$ Triton X-100 to remove the SDS, and incubated in buffer $(50 \mathrm{mM}$ Tris- $\mathrm{Cl}$, pH $8.0,50 \mathrm{mM} \mathrm{NaCl}$, and $10 \mathrm{mM} \mathrm{CaCl}_{2}$ ) in a $37^{\circ} \mathrm{C}$ water bath for $24 \mathrm{~h}$ to degrade the gelatin. The gel was then removed from the zymogram incubation buffer and stained in ethanolbased Coomassie Blue solution for $1 \mathrm{~h}$ to observe the lysis band.

Invasion assay. The assay used here was described by $\mathrm{Yu}$ et al (38). Briefly, G8 cells were grown in collagen coated 6-well plates until the monolayers were confluent, and then fixed with $20 \%$ dimethyl sulfoxide in methanol for $1 \mathrm{~h}$. After washing with PBS, the MDA-MB-435s cells $\left[2 \times 10^{5}\right.$ cells with or without CD44 crosslinking for $12 \mathrm{~h}$ or with or without pretreatment with rabbit anti-MMP-9 polyclonal $\mathrm{Ab}$ (10 $\mu \mathrm{g} / \mathrm{ml}$ ), MMP inhibitor GM6001 (Chemicon, Temecula, CA) (0.2 nM), or MMP inhibitor 1,10-phenanthroline (Sigma, St. Louis, MO) (2.5 mM) for $1 \mathrm{~h}$ before CD44 crosslinking] were added to the fixed cell layer and incubated in a $\mathrm{CO}_{2}$ incubator for 6 days, and then observed with a phase contrast microscope.

\section{Results}

MMP-9 level and zymogram detection of active MMP-9 in breast tumor cells after CD44 crosslinking. To evaluate the effect of CD44 crosslinking on the cellular level of MMP-9 as a function of time, human breast tumor cells (MDA-MB435s) were incubated with mouse anti-CD44 $\mathrm{mAb}$ for $1 \mathrm{~h}$ and goat anti-mouse IgG Fc Ab for 6, 9, 12, 24 h to crosslink the CD44 receptors. After goat anti-mouse IgG Fc Ab addition, the protease-containing subcellular fractions and serum-free medium were collected and subjected to Western blot analyses. Prior to CD44 crosslinking, MMP-9 (molecular weight ca. $92 \mathrm{kDa}$ ) is detected in the membrane of MDA-MB-345s cells (Fig. 1A). A gradual increase in the CD44 receptor crosslinking time from 1 to $24 \mathrm{~h}$ resulted in an increased amount of MMP-9 in the membrane faction (Fig. 1A) reaching a maximum after $12 \mathrm{~h}$ of CD44 receptor crosslinking to decrease by $24 \mathrm{~h}$ of CD 44 crosslinking (Fig. 1A). Western blot analyses of the lyophilized serum-free medium fraction demonstrated that for all the time points tested, the level of the MMP-9 was highest at $24 \mathrm{~h}$ of crosslinking (Fig. 1B).

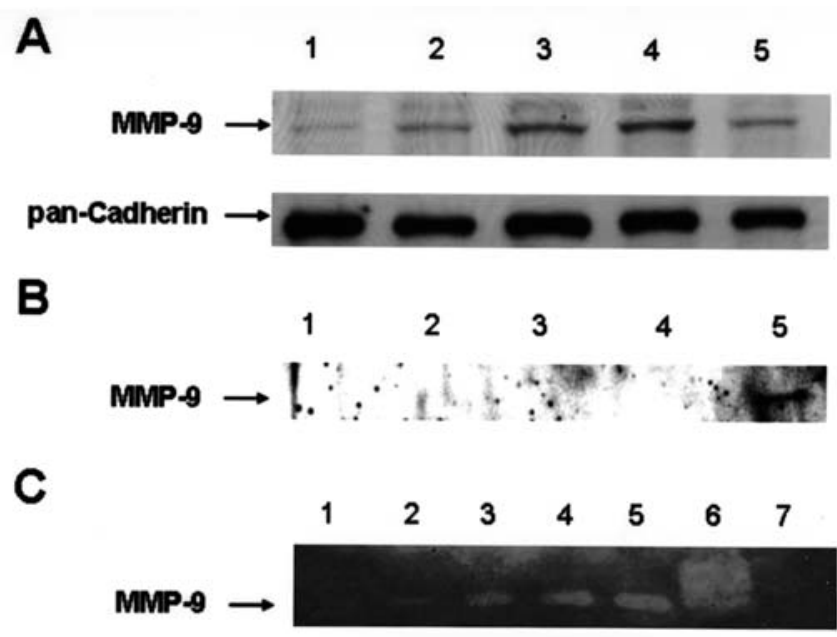

Figure 1. Evaluation of the MMP-9 levels in the membrane of MDA-MB435s human breast tumor cells after CD44 crosslinking for 1-24 h. The crosslinking of CD44 receptors in MDA-MB-435s cells was performed for $6,9,12$, or $24 \mathrm{~h}$ and the levels of MMP-9 in (A) cell membrane and (B) serum-free medium were detected by Western blotting. Lane 1, control group without CD44 crosslinking; lanes 2-5, CD44 crosslinking for 6, 9, 12 , and $24 \mathrm{~h}$, respectively. The relative intensity of the bands in lanes $2-5$ was $2.8,4.1,5.6$, and 3.3 , respectively (the intensity of the control band in lane 1 was set at 1). (C) CD44 receptors of MDA-MB-435s cells were stimulated for 3-36 h. Serum-free medium was collected and zymograms were used to assess MMP-9 activity after 3, 6, 9, 12, 24, and 36 h CD44 crosslinking (lanes 1-6, respectively). Lane 7 contained the control when no crosslinking was applied.

Furthermore, gelatin zymogram analyses were performed after 3, 6, 9, 12, 24, and $36 \mathrm{~h}$ of CD44 crosslinking; samples of serum-free medium were collected along with samples from the corresponding control (Fig. 1C). Through the Coomassie blue-stained background proteins, the MMP-9 lysis band was distinguishable at $24 \mathrm{~h}$ of CD44 receptor crosslinking. The MMP-9 level was highest at $24 \mathrm{~h}$ of CD44 crosslinking (Fig. 1C).

CD44 crosslinking enhances the level of MMP-9 at the breast tumor cell surface. After $12 \mathrm{~h}$ of CD44 crosslinking, MDA-MB-435s cells were trypsinized and the resulting suspension was treated with rabbit anti-MMP-9 polyclonal antibody, followed by FITC-conjugated goat anti-rabbit Ab, and analyzed by flow cytometry. No MMP-9 was detected in control MDA-MB-435s cells that were not subject to CD44 crosslinking nor in negative control cells that were not subject to CD44 crosslinking and that were not incubated with secondary FITC-conjugated goat anti-rabbit Ab (Fig. 2A). In contrast, a large amount of MMP-9 was found on the surface of cells after $12 \mathrm{~h}$ of CD44 crosslinking (Fig. 2B).

Colocalization of MMP-9 and CD44 after 12 h CD44 crosslinking. To investigate the possible colocalization of MMP-9 after $12 \mathrm{~h}$ of CD44 receptor crosslinking, MDA-MB-435s cells were fixed, blocked, and incubated with mouse antiCD44 mAb and rabbit anti-MMP-9 pAb at room temperature. Control cells were treated with rhodamine-conjugated donkey anti-mouse $\mathrm{Ab}$, while the cells with crosslinked CD44 were treated with FITC-conjugated goat anti-rabbit $\mathrm{Ab}$ and observed using a confocal microscope. Cells that did not 
$\mathbf{A}$

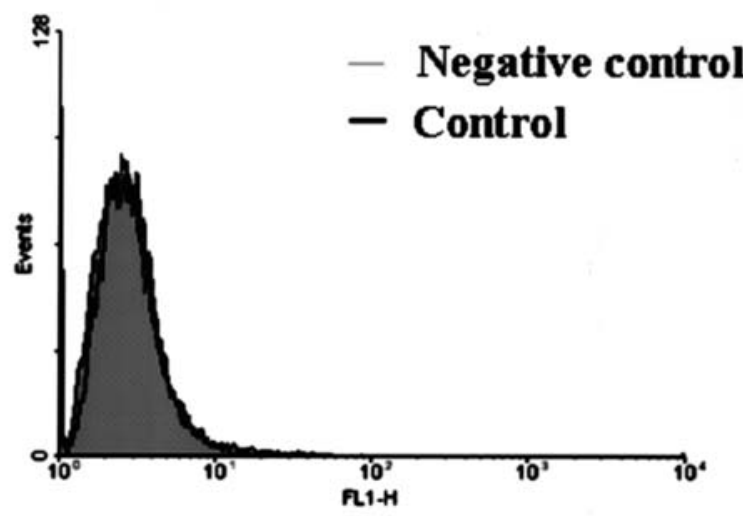

B

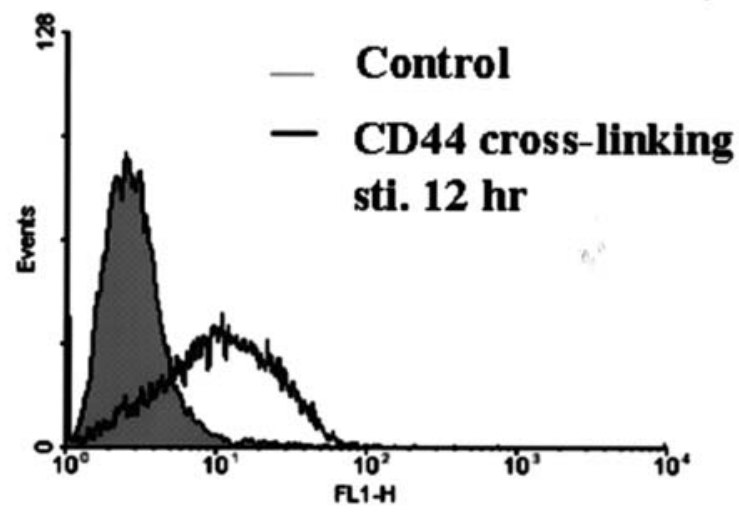

Figure 2. Evaluation of the MMP-9 level on cell membranes of MDA-MB-435s cells after 12 h CD 44 crosslinking by flow cytometry. Comparison between (A) the control cells without CD44 crosslinking and the negative control in which the second antibody was omitted; and (B) the control cells and stimulated cells after $12 \mathrm{~h}$ of CD 44 crosslinking.

undergo CD44 crosslinking were found to have CD44 receptors on their membranes (Fig. 3B) and MMP-9 in their cytosols (Fig. 3A) as confirmed by the composit image (Fig. 1C). Cells with CD44 receptor crosslinking were found to have caps of CD44 (Fig. 3E) and large amounts of MMP-9 on their membranes (Fig. 3D) which was confirmed by the composit image (Fig. 3F).

Immunoprecipitation of the CD44-MMP-9 complex after CD44 crosslinking. Subcellular fractions and culture medium of MDA-MB-435s cells were collected after $12 \mathrm{~h}$ of CD44 crosslinking and the CD44 protein complexes were immunoprecipitated with mouse anti-CD44 mAb coupled to protein A-agarose beads. Proteins binding to CD44 receptors were purified and analyzed by Western blotting using rabbit antiMMP-9 to observe the interaction between CD44 receptor and MMP-9 showed that MMP-9 is on the cell membranes of breast tumor cells after CD44 crosslinking for $12 \mathrm{~h}$. This biochemical experiment supports the colocalization study and suggests that the $92-\mathrm{kDa}$ MMP-9 and CD44 receptor appear as a complex on the cell membrane (Fig. 3G).

Effect of cycloheximide on induction of MMP-9 expression by CD44 crosslinking. MDA-MD-435s cells were treated with $20 \mu \mathrm{g} / \mathrm{ml}$ of the protein synthesis inhibitor cycloheximide
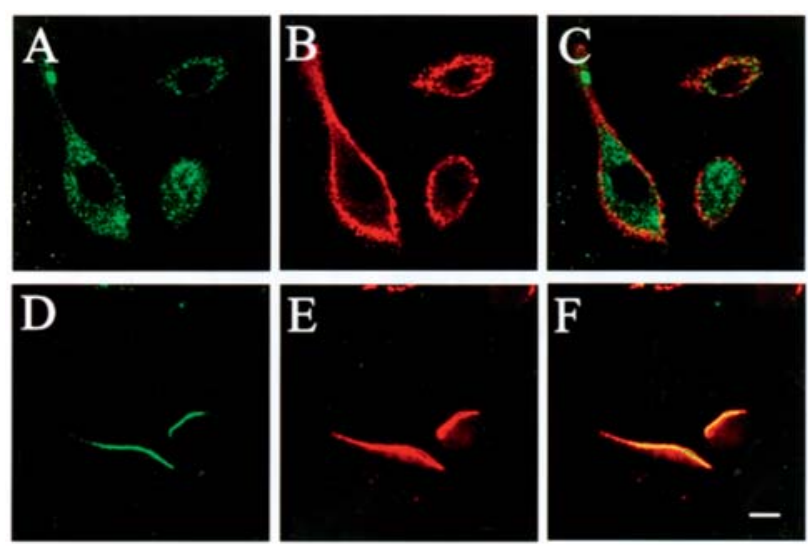

G
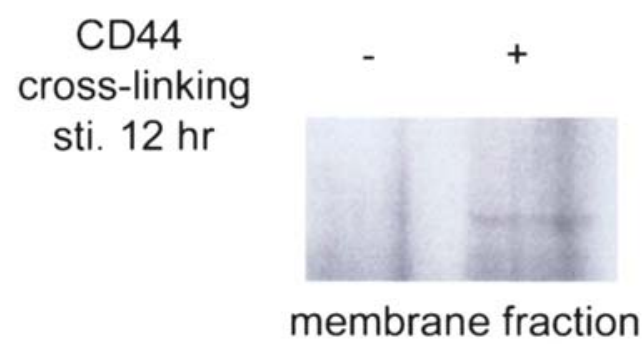

Figure 3. Localization of CD44 and MMP-9 in MDA-MB-435s cells after CD44 crosslinking for $12 \mathrm{~h}$. Double immunofluorescent staining of (A) MMP-9 and (B) CD44 in control cells, and (D) MMP-9 and (E) CD44 in cells after CD44 crosslinking for $12 \mathrm{~h}$. (C) is a composite image of (A) and (B), while (F) is a composite image of (D) and (E). (Scale bar, $10 \mu \mathrm{m}$.). (G) After $12 \mathrm{~h}$ of CD44 crosslinking, mouse anti-CD44 mAb and protein A agarose beads were added to immunoprecipitate CD44, and the expression of MMP-9 was found to be colocalized with CD44 on cell membranes.
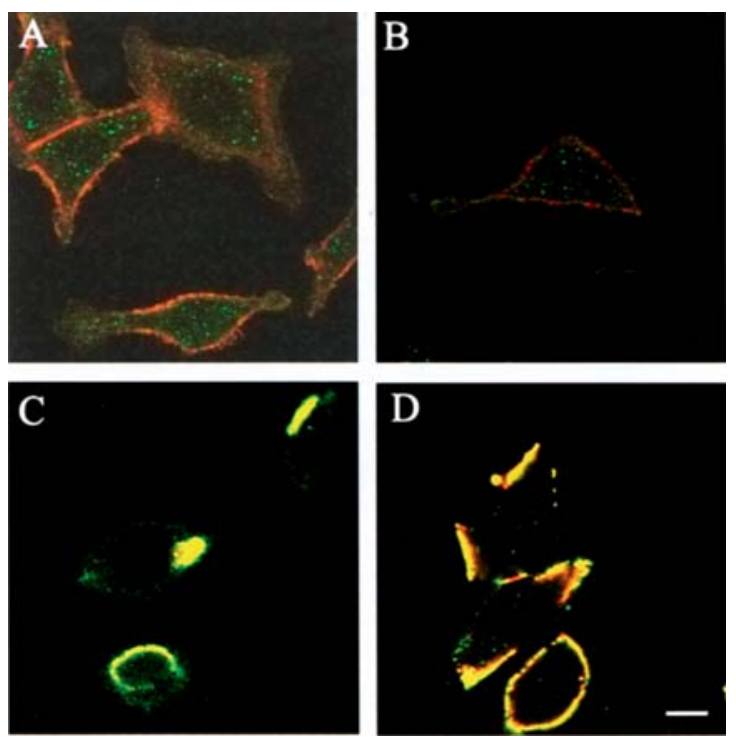

Figure 4. Localization of MMP-9 in MDA-MB-435s cells after treatment with cycloheximide followed by CD44 crosslinking for $12 \mathrm{~h}$. Double immunofluorescent staining to observe the localization of CD44 receptor (red) and MMP-9 (green) in MDA-MB-435s cells. A, control; B, cells treated with cycloheximide; C, CD44 crosslinking without the addition of cycloheximide; D, cells first treated with cycloheximide followed by $12 \mathrm{~h}$ CD44 crosslinking. Scale bar, $10 \mu \mathrm{m}$. 

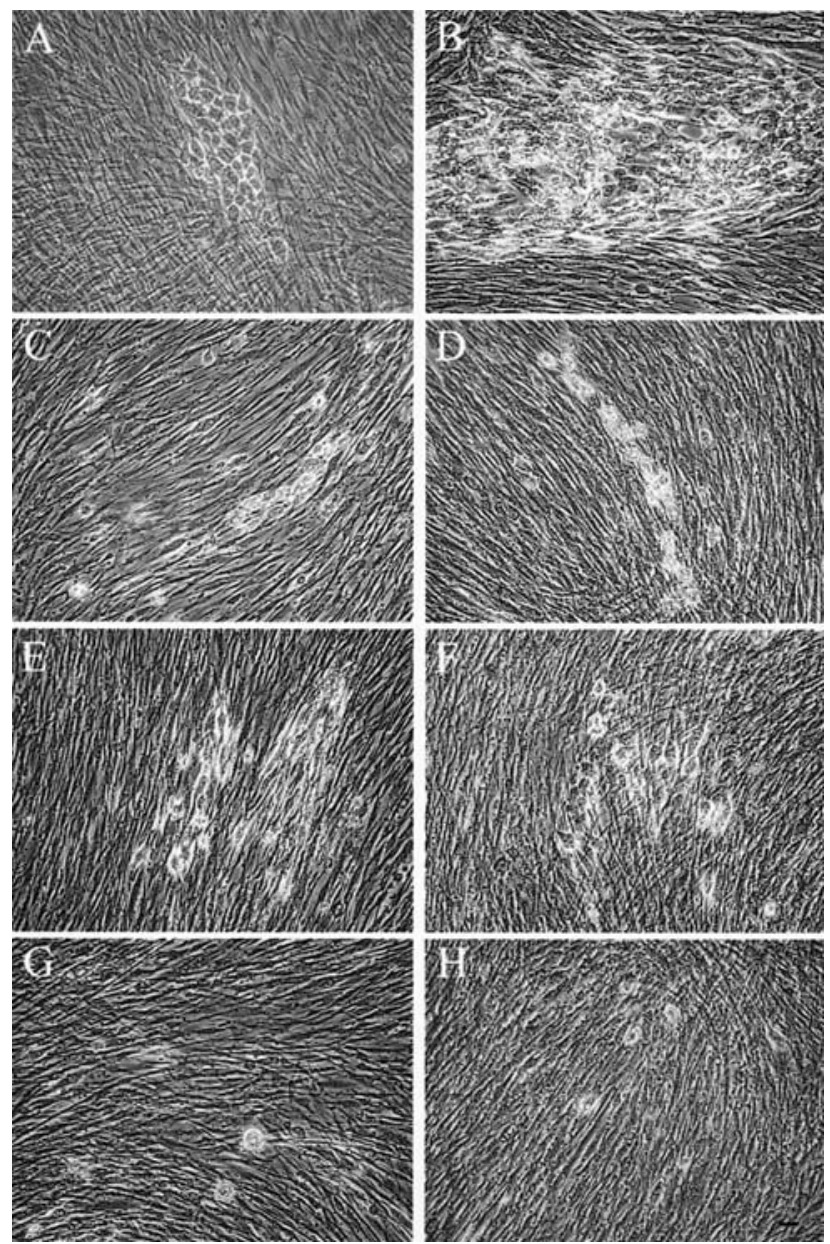

Figure 5. Invasion of G8 myoblast monolayers by breast tumor cells. Tumor cell islets (arrow, breast tumor cells) were observed to invade the monolayer 6 days after being seeded with breast tumor cells. Before seeding dimethyl sulfoxide-fixed G8 monolayers with MDA-MB-435s cells, the latter were or were not subjected to $\mathrm{CD} 44$ crosslinking at $37^{\circ} \mathrm{C}$ for $12 \mathrm{~h}$. A, Control, breast tumor cells; B, stimulated by CD44 crosslinking for $12 \mathrm{~h}$; C, treated with rabbit anti-MMP-9 pAb $(10 \mu \mathrm{g} / \mathrm{ml})$; D, pretreated with rabbit anti-MMP-9 $\mathrm{pAb}(10 \mu \mathrm{g} / \mathrm{ml})$, before CD44 crosslinking; E, treated with MMP inhibitor, GM6001 (0.2 nM); F, treated with MMP inhibitor, GM6001 (0.2 nM), before CD44 crosslinking; G, treated with 1,10-phenanthroline $(2.5 \mathrm{mM})$; and $\mathrm{H}$, treated with for 1,10-phenanthroline before CD44 crosslinking. Scale bar, $10 \mu \mathrm{m}$.

for $1 \mathrm{~h}$, subject to $12 \mathrm{~h}$ of CD44 crosslinking, fixed, blocked, and treated with mouse anti-CD44 mAb and goat anti-MMP-9 $\mathrm{pAb}$ for $1 \mathrm{~h}$ at room temperature. The control cells (without crosslinking) were treated with rhodamine-conjugated donkey anti-mouse $\mathrm{Ab}$ for $1 \mathrm{~h}$ at room temperature. Both the CD44-crosslinked MDA-MD-435s cells and control cells were incubated with FITC-conjugated goat anti-rabbit Ab at room temperature for $1 \mathrm{~h}$. The intracellular localization of MMP-9 and CD44 was evaluated by confocal microscopy.

The results showed that prior to CD44 crosslinking, CD44 is found on MDA-MB-435s cell membranes while MMP-9 is found inside cells (Fig. 4A); treatment with cycloheximide did not alter this distribution (Fig. 4B). In addition, after $12 \mathrm{~h}$ of CD44 crosslinking, CD44 receptor and MMP-9 were found to be colocalized on cell membranes (Fig. 4C) and this distribution was not affected by cycloheximide (Fig. 4D). These observations suggest that CD44 crosslinkingmediated effects on MMP-9 do not require protein synthesis.
Effect of CD44 crosslinking on breast tumor cell invasion of adjacent myoblast monolayers. After addition of protease inhibitor [rabbit anti-MMP-9 polyclonal Ab $(10 \mu \mathrm{g} / \mathrm{ml})$, MMP inhibitor GM6001 (0.2 nM) or MMP inhibitor 1,10 phenanthroline $(2.5 \mathrm{mM})$ ] to breast tumor cells without or with crosslinking for $12 \mathrm{~h}, 2.5 \times 10^{2}$ cells were collected and seeded on a G8 myoblast monolayer. Taking advantage of G8 myoblast's ability to form large amounts of substrate, we observed that the tumor cells were capable of invading adjacent healthy tissues, forming a colony with a complete and more rounded periphery (Fig. 5A). After $12 \mathrm{~h}$ of CD44 crosslinking, the ability of the tumor cells to invade adjacent tissues was noticeably enhanced, i.e., the colonies formed were larger, irregular, and had incomplete borders (Fig. 5B). This finding suggests that crosslinking of CD44 receptors stimulates tumor cells to invade adjacent tissues. The importance of matrix metalloprotease is clearly shown by the large amount of MMP-9 found on cell membranes after CD44 crosslinking. In this experiment, breast tumor cells were first incubated in rabbit anti-MMP-9 pAb and then subjected to crosslinking. It was observed that the invasive ability of the breast tumor cells was initially enhanced but subsequently became significantly repressed (Fig. 5C and D). In addition, the invasion ability of MDA-MB-435s cells treated with GM6001 and then subjected to CD44 crosslinking was reduced to the point where only small colonies could be formed (Fig. 5E and F). Similarly, the invasive ability of MDA-MB-435s cells treated with 1,10-phenanthroline before CD44 crosslinking was entirely eliminated (Fig. 5G and H). These findings suggest that breast tumor cell invasion involves a process of MMP-9 redistribution in response to $\mathrm{CD} 44$ receptor crosslinking.

\section{Discussion}

In this study, we demonstrate for the first time in breast tumor cells that: i) crosslinking of CD44 on human breast tumor MDA-MB-435s cells enhances the relocalization of MMP-9 on cell membrane and ii) an increase of the MMP-9 level and its relocation after CD44 crosslinking stimulates breast tumor cell invasion of adjacent normal tissues and metastasis.

CD44 receptors are multifunctional involved in direct cell-cell and cell-substrate interactions, and serve as the main hyaluronan receptor on cell membranes. The stimulation of CD44 receptors by hyaluronan on human alveolar macrophages is molecular weight-dependent. Hyaluronan with smaller molecular weights was found to induce the expression of chemokine gene on human alveolar macrophages (39) and the expression of MMP-encoding genes in murine 3LL tumor cells (32). In other experiments, hyaluronan with different molecular weights was shown to stimulate nuclear factor- $\kappa \mathrm{B}-$ and activating protein-1-mediated expression of VCAM-1 and ICAM-1 in mouse murine kidney tubular epithelial cells (19). We discovered that CD44 crosslinking induces integrinmediated adhesion and transendothelial migration (40). These observations suggest that the signaling function of hyaluronan likely depends on its molecular weight.

Besides the ligand-mediated activation of CD44, it is also possible to activate CD44 by antibody-mediated crosslinking. 
Indeed, Galandrini et al (41) used antibodies to stimulate the CD44 receptors on the human NK cell and enhanced cytotoxicity and Fujii et al (20) used antibodies for CD44 crosslinking in rheumatoid synovial fibroblasts to upregulate VCAM-1 expression. Here, we applied mouse anti-human CD44 mAb and goat anti-mouse IgG Fc antibody for CD44 crosslinking. Crosslinking acts as a CD44 receptor stimulant, thereby increasing the efficiency of signaling.

In breast cancer patients, tumor cells often metastasize to the bone. Saad et al (42) studied in vitro cocultures to determine the relationship between tumor cells and bone marrow fibroblasts. The tumors cells can use MMPs to enter capillaries, invade the tissue, and increase the area of the tumor, rendering cancer treatment more difficult (27). MMP-1 and MMP-2 were found to be present in substantial amounts in the medium which may possibly be perceived as a signal for breast tumor cells to penetrate the cellular layer and enter the bone marrow (42). In addition, evidence obtained from in vitro and in vivo experiments suggests that CD44 plays an important role in the preferential spread of metastatic breast cancer cells to the skeleton (43).

When breast tumor cells undergo CD44 crosslinking, the time of CD44 crosslinking is correlated with an increase of the cellular level of MMP-9 which peaked after $12 \mathrm{~h}$ of CD44 crosslinking, whereas of all time-points tested, the accumulation of MMP-9 in serum-free medium was highest at $24 \mathrm{~h}$ of stimulation. After CD44 crosslinking, large amounts of MMP-9 accumulate in the medium and cell membrane. Zymogram analyses showed that after $24 \mathrm{~h}$ of CD44 crosslinking, more of the more-active form of MMP-9 can be found, which corresponds to our Western blot results. Seftor et al (44) discovered that stimulating human melanoma avB3 integrin increased the expression of MMP-2 and CD44 receptor stimulation in human melanoma increased expression of MMP-2 (45). These studies showed that stimulating adhesion molecules induces the production of proteases and is involved in the process of tumor cell invasion and migration. Thus, the biological effect of CD44 crosslinking varies with cell type and duration of stimulation.

Remarkably, no MMP-9 was detectable by flow cytometry in tumor cells that did not undergo CD44 crosslinking which may be due to its very low presence on cell surfaces. Under normal circumstances, a small amount of MMP-9 is detectable by Western blotting; this may be because the protease is collected from the entire cell, thus magnifying the signal. After $12 \mathrm{~h}$ of CD44 crosslinking, MMP-9 was found to be highly expressed on the cell membrane, thus proving that signaling occurs after CD44 receptor stimulation and induces MMP-9 expression on cell membranes.

It is noteworthy that CD44 receptors and MMP-9 clustered and colocalized. What is the biological consequence of this phenomenon in respect to the development of breast tumor cells? In the MMP-9 family, other than membrane MMPs that anchor to cell surfaces, most MMPs are secreted (28). Brooks et al (46) discovered that $\alpha \mathrm{v} B 3$ integrin induces MMP-2 to localize on cell surfaces and overproduction of CD44 receptor in mouse mammary carcinoma and human melanoma cells led to the discovery that CD44 receptor and MMP-9 colocalize on cell membranes (31). Therefore, adhesion molecules can induce soluble MMPs to bind to cell membranes and use their proteolytic activity to enchance cell invasion. Our study showed that CD44 crosslinking induced MMP-9 expression on breast tumor cell membranes and that CD44 receptors are used as a docking site to allow MMP-9 to exert protease activity on cell membranes thereby stimulating metastasis.

During CD44 crosslinking, protein A and mouse anti-CD44 $\mathrm{mAb}$ were used to form immunocomplexes. The expression of MMP-9 was detected on cell membranes after CD44 crosslinking. As described above, immunofluorescence revealed signs of MMP-9 and CD44 receptor association on the cell surface. In cytosol, this phenomenon was undetectable, which proves that MMP-9 induced by CD44 crosslinking did not form complexes with CD44 receptors in cytosol but interacted only at the cell surface. In the medium of the stimulated cells, low MMP-9 expression might be the soluble complexes of CD44 and MMP-9 formed through immunoprecipitation.

To analyze CD44 crosslinking-induced MMP-9 expression and its relationship to the invasive ability of human breast tumor cells, G8 myoblast was co-cultured with stimulated breast tumor cells or those treated with protease inhibitors. The invasive ability of human breast tumor cells increased after CD44 crosslinking, in that colonies grew larger and their outer edges became more ragged. This phenomenon was inhibited by the addition of the MMP inhibitors (GM6001 and 1,10-phenanthroline), which shows that MMP-9 is an active participant in the tumor invasion process. Because the above-mentioned inhibitors affect all MMPs, other cells were preincubated with rabbit anti-MMP-9 pAb before stimulating their CD44 receptors; the enhancement of tumor cell invasion ability of these cells was significantly inhibited. Clearly, the enhancement of invasive ability is directly related to MMP-9 expression. The co-capping of MMP-9 and CD44 receptors can be found on cell membranes where they promote the invasion and migration.

MMP-2, MMP-9, MMP-1, and MTI-MMP are known to be active in the progression of cancer, and MMP-2 and MMP-9 are often used as markers for breast and intestinal tumors $(47,48)$. CD44 expression was shown to be elevated in migratory breast tumors as copared to normal breast tissue $(49,50)$. We found that the invasive and migratory abilities of human breast tumor cells can be enhanced by CD44 crosslinking, which causes CD44 signaling, enhanced MMP-9 production on cell membranes and in the medium, and induction of co-capping with MMP-9. This study does not only contribute to our understanding of important molecular mechanisms of human breast tumor development and metastasis, but also provides novel thoughts that will fuel investigations dedicated to the development of therapeutic strategies to ameliorate breast cancer, such as the design of small molecules that interfere with the cellular relocation of MMP-9 upon CD44 receptor activation.

\section{Acknowledgments}

This work was supported in part by grant NSC 92-2320-B010-036 from the National Science Council and a grant from the Ministry of Education, Aim for the Top University Plan, Taiwan, to H.-S. Wang. 


\section{References}

1. Crawford NPS and Hunter KW: New perspectives on hereditary influences in metastatic progression. Trends Genet 22: 555-561, 2006.

2. Deryugina EI and Quigley JP: Matrix metalloproteinases and tumor metastasis. Cancer Metastasis Rev 25: 9-34, 2006.

3. Dalchau R, Kirkley J and Fabre JW: Monoclonal antibody to a human brain-granulocyte-T lymphocyte antigen probably homologous to the W 3/13 antigen of the rat. Eur J Immunol 10: 745-749, 1980 .

4. Screaton GR, Bell MV, Jackson DG, Cornelis FB, Gerth U and Bell JI: Genomic structure of DNA encoding the lymphocyte homing receptor CD44 reveals at least 12 alternatively spliced exons. Proc Natl Acad Sci USA 89: 12160-12164, 1992.

5. Jackson DG, Buckley J and Bell JI: Multiple variants of the human lymphocyte homing receptor CD44 generated by insertions at a single site in the extracellular domain. J Biol Chem 267: 4732-4739, 1992.

6. Droll A, Dougherty ST, Chiu RK, Dirks JF, McBride WH, Cooper DL and Dougherty GJ: Adhesive interactions between alternatively spliced CD44 isoforms. J Biol Chem 270: 11567-11573, 1995.

7. Peach RJ, Hollenbaugh D, Stamenkovic I and Aruffo A: Identification of hyaluronic acid binding sites in the extracellular domain of CD44. J Cell Biol 122: 257-264, 1993.

8. Bartolazzi A, Peach R, Aruffo A and Stamenkovic I: Interaction between CD44 and hyaluronate is directly implicated in the regulation of tumor development. J Exp Med 180: 53-66, 1994.

9. Romaris M, Bassols A and David G: Effect of transforming growth factor-beta 1 and basic fibroblast growth factor on the expression of cell surface proteoglycans in human lung fibroblasts. Enhanced glycanation and fibronectin-binding of CD44 proteoglycan, and down-regulation of glypican. Biochem J 310: 73-81, 1995.

10. Hathcock KS, Hirano H, Murakami S and Hodes RJ: CD44 expression on activated B cells. Differential capacity for CD44dependent binding to hyaluronic acid. J Immunol 151: 6712-6722, 1993.

11. Liao HX, Levesque MC, Patton K, et al: Regulation of human $\mathrm{CD} 44 \mathrm{H}$ and CD44E isoform binding to hyaluronan by phorbol myristate acetate and anti-CD44 monoclonal and polyclonal antibodies. J Immunol 151: 6490-6499, 1993.

12. Zahalka MA, Okon E, Gosslar U, Holzmann B and Naor D: Lymph node (but not spleen) invasion by murine lymphoma is both CD44- and hyaluronate-dependent. J Immunol 154: 5345-5355, 1995 .

13. Haynes BF, Telen MJ, Hale LP and Denning SM: CD44 - a molecule involved in leukocyte adherence and T-cell activation. Immunol Today 10: 423-428, 1989.

14. Haynes BF, Liao HX and Patton KL: The transmembrane hyaluronate receptor (CD44): multiple functions, multiple forms. Cancer Cell 3: 347-350, 1991.

15. Galandrini R, Galluzzo E, Albi N, Grossi CE and Velardi A: Hyaluronate is costimulatory for human $\mathrm{T}$ cell effector functions and binds to CD44 on activated T cells. J Immunol 153: 21-31, 1994.

16. Turley EA, Noble PW and Bourguignon LYW: Signaling properties of hyaluronan receptors. J Biol Chem 277: 4589-4592, 2002.

17. Horst E, Meijer CJ, Radaskiewicz T, et al: Expression of a human homing receptor (CD44) in lymphoid malignancies and related stages of lymphoid development. Leukemia 4: 383-389, 1990.

18. Horst E, Meijer CJ, Radaszkiewicz T, Ossekoppele GJ, van Krieken JH and Pals ST: Adhesion molecules in the prognosis of diffuse large-cell lymphoma: expression of a lymphocyte homing receptor (CD44), LFA-1 (CD11a/18), and ICAM-1 (CD54). Leukemia 4: 595-599, 1990.

19. Oertli B, Beck-Schimmer B, Fan X and Wuthrich RP: Mechanisms of hyaluronan-induced up-regulation of ICAM-1 and VCAM-1 expression by murine kidney tubular epithelial cells: hyaluronan triggers cell adhesion molecule expression through a mechanism involving activation of nuclear factorkappa B and activating protein-1. J Immunol 161: 3431-3437, 1998.

20. Fujii K, Tanaka Y, Hubscher S, Saito K, Ota T and Eto S: Crosslinking of CD44 on rheumatoid synovial cells up-regulates VCAM-1. J Immunol 162: 2391-2398, 1999.
21. Fujisaki T, Tanaka Y, Fujii K, et al: CD44 stimulation induces integrin-mediated adhesion of colon cancer cell lines to endothelial cells by up-regulation of integrins and c-Met and activation of integrins. Cancer Res 59: 4427-4434, 1999.

22. Bourguignon LY, Zhu H, Shao L and Chen YW: AnkyrinTiam 1 interaction promotes Rac1 signaling and metastatic breast tumor cell invasion and migration. J Cell Biol 150: 177-191, 2000.

23. Fitzgerald KA, Bowie AG, Skeffington BS and O'Neill LA: Ras, protein kinase $\mathrm{C}$ zeta, and I kappa B kinases 1 and 2 are downstream effectors of CD44 during the activation of NFkappa B by hyaluronic acid fragments in T-24 carcinoma cells. J Immunol 164: 2053-2063, 2000.

24. Gunthert U, Hofmann M, Rudy W, et al: A new variant of glycoprotein CD44 confers metastatic potential to rat carcinoma cells. Cell 65: 13-24, 1991.

25. Sy MS, Guo YJ and Stamenkovic I: Distinct effects of two CD44 isoforms on tumor growth in vivo. J Exp Med 174: 859-866, 1991.

26. Varner JA and Cheresh DA: Integrins and cancer. Curr Opin Cell Biol 8: 724-730, 1996.

27. Mignatti P and Rifkin DB: Biology and biochemistry of proteinases in tumor invasion. Physiol Rev 73: 161-195, 1993.

28. Van den Steen PE, Dubois B, Nelissen I, Rudd PM, Dwek RA and Opdenakker G: Biochemistry and molecular biology of gelatinase B or matrix metalloproteinase-9 (MMP-9). Crit Rev Biochem Mol Biol 37: 375-536, 2002.

29. Allan JA, Docherty AJ, Barker PJ, Huskisson NS, Reynolds JJ and Murphy G: Binding of gelatinases A and B to type-I collagen and other matrix components. Biochem J 309: 299-306, 1995.

30. Steffensen B, Wallon UM and Overall CM: Extracellular matrix binding properties of recombinant fibronectin type II-like modules of human 72-kDa gelatinase/type IV collagenase. High affinity binding to native type I collagen but not native type IV collagen. J Biol Chem 270: 11555-11566, 1995.

31. Yu Q and Stamenkovic I: Cell surface-localized matrix metalloproteinase-9 proteolytically activates TGF-beta and promotes tumor invasion and angiogenesis. Genes Dev 14: 163-176, 2000.

32. Fieber C, Baumann P, Vallon R, et al: Hyaluronan-oligosaccharide-induced transcription of metalloproteases. J Cell Sci 117: 359-367, 2004

33. Cabrera PV, Blanco G, Alaniz L, Greczanik S, Garcia M, Alvarez E and Hajos SE: CD44 and hyaluronic acid regulate in vivo iNOS expression and metalloproteinase activity in murine air-pouch inflammation. Inflamm Res 53: 556-566, 2004.

34. Murray D, Morrin M and McDonnell S: Increased invasion and expression of MMP-9 in human colorectal cell lines by a CD44dependent mechanism. Anticancer Res 24: 489-494, 2004.

35. Karadag A, Fedarko NS and Fisher LW: Dentin matrix protein 1 enhances invasion potential of colon cancer cells by bridging matrix metalloproteinase-9 to integrins and CD44. Cancer Res 65: 11545-11552, 2005

36. Annabi B, Bouzeghrane M, Currie J-C, et al: A PSP94-derived peptide PCK3145 inhibits MMP-9 secretion and triggers CD44 cell surface shedding: implication in tumor metastasis. Clin Exp Metastasis 22: 429-439, 2005.

37. Shi YE, Torri J, Yieh L, Wellstein A, Lippman ME and Dickson RB: Identification and characterization of a novel matrix-degrading protease from hormone-dependent human breast cancer cells. Cancer Res 15: 1409-1415, 1993.

38. Yu Q, Toole BP and Stamenkovic I: Induction of apoptosis of metastatic mammary carcinoma cells in vivo by disruption of tumor cell surface CD44 function. J Exp Med 186: 1985-1996, 1997.

39. McKee CM, Penno MB, Cowman M, Burdick MD, Strieter RM, Bao C and Noble PW: Hyaluronan (HA) fragments induce chemokine gene expression in alveolar macrophages. The role of HA size and CD44. J Clin Invest 98: 2403-2413,1996.

40. Wang H-S, Hung Y, Su C-H, et al: CD44 crosslinking induces integrin-mediated adhesion and transendothelial migration in breast cancer cell line by up-regulation of LFA-1 ( $\alpha$ LB2) and VLA-4 ( $\alpha 431)$. Exp Cell Res 304: 116-126, 2005

41. Galandrini R, De Maria R, Piccoli M, Frati L and Santoni A CD44 triggering enhances human NK cell cytotoxic functions. J Immunol 153: 4399-4407, 1994.

42. Saad S, Bendall LJ, James A, Gottlieb DJ and Bradstock KF Induction of matrix metalloproteinases MMP-1 and MMP-2 by co-culture of breast cancer cells and bone marrow fibroblasts. Breast Cancer Res Treat 63: 105-115, 2000. 
43. Hill A, McFarlane S, Johnston PG and Waugh DJJ: The emerging role of CD44 in regulating skeletal micrometastasis. Cancer Lett 237: 1-9, 2006.

44. Seftor RE, Seftor EA, Stetler-Stevenson WG and Hendrix MJ: The $72 \mathrm{kDa}$ type IV collagenase is modulated via differential expression of alpha v beta 3 and alpha 5 beta 1 integrins during human melanon cell invasion. Cancer Res 53: 3411-3415, 1993.

45. Takahashi K, Eto H and Tanabe KK: Involvement of CD44 in matrix metalloproteinase- 2 regulation in human melanoma cells. Int J Cancer 80: 387-395, 1999

46. Brooks PC, Silletti S, von Schalscha TL, Friedlander M and Cheresh DA: Disruption of angiogenesis by PEX, a noncatalytic metalloproteinase fragment with integrin binding activity. Cell 92: 391-400, 1998.
47. Zucker S, Hymowitz M, Conner C, et al: Measurement of matrix metalloproteinases and tissue inhibitors of metalloproteinases in blood and tissues. Clinical and experimental applications. Ann NY Acad Sci 878: 212-227, 1999.

48. Davies B, Miles DW, Happerfield LC, Naylor MS, Bobrow LG, Rubens RD and Balkwill FR: Activity of type IV collagenases in benign and malignant breast disease. Br J Cancer 67: 1126$1131,1993$.

49. Iida $\mathrm{N}$ and Bourguignon LY: New CD44 splice variants associated with human breast cancers. J Cell Physiol 162: 127133,1995

50. Naot D, Sionov RV and Ish-Shalom D: CD44: structure, function, and association with the malignant process. Adv Cancer Res 71: 241-319, 1997. 